\title{
Tobias Nanz
}

\section{Disrupted Arts and Marginalized Humans}

\section{A Commentary on Friedrich Kittler's "Signal-to-Noise Ratio"}

A commentary on Friedrich Kittler's essay, "Signal-to-Noise Ratio" (for a reprint see this volume: 347-361), is necessarily intimately bound up with the topic of the essay in question, since in the semantic sense every commentary aims to establish a signal-to-noise ratio. Michel Foucault understood the commentary as an instrument that controls and restricts a discourse, that unearths and elaborates what was already silently articulated in it. Thus, "fundamental and creative discourses" (Foucault 1981: 57) are repeated and confirmed, since the same signals and messages are always filtered out of a background noise of countless possible meanings. Following on from this, Kittler was particularly interested in the way in which technical media are involved in the formation of discourses. He coined the term "discourse network," which "designate[s] the network of technologies and institutions that allow a given culture to select, store, and process relevant data" (Kittler 1990: 369). Thus, every author is embedded in a specific contemporary or historical context and network in which the media s/he uses/used to write his/her texts are relevant actors in the discourse network. In Kittler's case, as from the 1980s these media were the electric typewriter, the personal computer and word processor, which transformed each of his texts into the binary code and displayed the writing on monitors or on the printed page, as a surface effect of algorithms (Kittler 1988: 298-299). In the current discourse network, an author's text production cannot be separated from the digital processing carried out by a computer. Thus, a commentary on Kittler's text can be interpreted literally and metaphorically as an adjustment of the signalto-noise ratio: from the noise of the sequences of 0 and 1 , a short text emerges on the screen or on paper, which filters out a specific message from numerous possible meanings.

"Signal-to-Noise Ratio" was first published in 1988 in the anthology Materiality of Communication [Materialität der Kommunikation], edited by Hans Ulrich Gumbrecht and K. Ludwig Pfeiffer, and sought to divert attention away from questions of hermeneutics and the search for meaning in texts to the materiality of the media, which are the conditions of possibility of communication, texts, and cultures (Gumbrecht and Pfeiffer 1988). Meaning, according to Kittler, would not exist without a physical medium that can establish communication,

Translated from the German by Gregory Sims. 
by which he means material media such as books as well as immaterial media such as electromagnetic waves. This shift in focus is designed to open up a perspective that, building on Foucault's discourse analysis, attempts to reveal the media-technical conditions of possibility of communication processes. Since Foucault's studies mostly did not cross the threshold of the twentieth century, Kittler's authority for the twentieth century is the mathematician Claude Shannon. His mathematical information theory dealt with the problem of how to transfer data without information loss, using electronic channels (e.g., telegraphy or telephony). In Shannon's case, the primary goal was to ensure a message is sent, that is to say, to describe the technical conditions of possibility of a signal transmission, and to provide the necessary mathematics - regardless of the significance of what the transmitter is sending to the receiver and regardless of the medium used to transmit the data. This bracketing out of the different modes of operation of the media - which, by contrast, play a fundamental role in Kittler's theory - is probably due to the war-time conditions in which Shannon's theory was conceived. The central premise was "get the message through," which, in accordance with mathematical information theory, was oriented towards the largest common denominator amongst many different channels and did not entail a subtle differentiation between media (Schüttpelz 2002: 64-65).

For the topic of the present volume, Kittler's text "Signal-to-Noise Ratio" appears interesting in three respects. Firstly, from Shannon's work it develops the aspect that is fundamental to the theory of the media, namely that disruption noise or interference - is a prerequisite for all communication. Consequently, Kittler no longer defines the process of reception and the interpretation of texts as a hermeneutic process, but rather as a processing of signals. Secondly, he discusses the effects of mathematical information theory on the arts, and, thirdly, examines the status of human beings in the context of the computerization of society.

Thus, first of all, Shannon's mathematical information theory is based on the fundamental assumption that a communication channel never operates without interference. Shannon developed this thought during the Second World War when working for the Bell Laboratories in the United States. There, he designed a communication model that described the transmission of information from a transmitter to a receiver with continuous background noise, which can be caused, for example, by the channel, by the media technology, or by atmospheric discharges (Shannon 1949). The signal-to-noise ratio defines the ratio of signal power to noise power, and thus indicates whether a useful signal - i.e., a signal not drowned out by noise - arrives at the receiver's end and can be filtered out. The higher the signal-to-noise ratio, the less interference there is impeding a signal from reaching its destination. Since then, successful communication has always had to be considered in the context of disruption. As 
epitomizing what he had in mind, Shannon introduced a noise source into his model, which was on the same level as the source of the sender, to which, if necessary, an encryption instrument is connected. Since Shannon was dealing at the same time with questions of encryption during the Second World War, his work resulted in a close link between communication theory and cryptography. In his essay, "Communication Theory of Secrecy Systems," he noted that from a cryptographic perspective "a secrecy system is almost identical with a noisy communication system" (Shannon 1991 [1946]: 113). The noise of the channel and the noise of the encrypted (and thereby disrupted) signal can in a way be added together, since an enemy intelligence service cannot distinguish between chaos (background noise) and strategy (noise deliberately introduced into the signal through encryption). Mathematically, both types of noise are thus approached in the same way (Winthrop-Young 2005: 140 -141).

The principal aspect for Kittler is that the premises of mathematical information theory are valid not only for the technical side of communication, but that the correct setting of a signal-to-noise ratio also holds true for the semantic side. Processes of understanding and the assigning of meaning function analogously to information-processing systems and have to filter out signals from noisy channels. For Kittler, understanding means signal processing; it is no longer a question of interpreting, but rather of encoding.

Secondly, this mathematization of understanding implies that the status of the arts would be opened to debate, since - as Shannon's approximations to the English language are intended to make clear - works of art are no longer solely created by humans, but can also be produced by technical agents. By means of his experiments, he showed how, with the help of Markov chains, English literature can be calculated on the basis of a defined character set such as the alphabet. Markov chains describe stochastic processes that can provide prognoses for future developments. If one includes in a calculation the probability for a specific language - of one letter of the alphabet being followed by another letter (in English, for instance, a meaningful word can never be created by placing an " $x$ " directly after a " $z$ "), this gives rise to individual word series, which may not necessarily engender meaning, but, as Kittler notes, they can compete with modern literature (as in Finnegans Wake). Thus, literature can also be calculated using mathematics, which - as Shannon formulates it - amounts to a "frontal attack on an English writer."

According to Kittler, this attack may have begun in the nineteenth century. Thus, on the one hand, the poetry of Goethe's time was characterized by the exclusion of noise, in the sense that voices or noises were transferred into the clearly defined sign system of the alphabet. Writing was supposed to ensure that the message reached its recipients and thus - thanks to discrete, noise-free letters of 
the alphabet - raised the signal-to-noise ratio to a maximum. This was not to remain the case, however. For, using the example of Fourier analysis, which was created at the beginning of the nineteenth century, Kittler develops the mathematics of art. Fourier analysis makes it possible to express all physical oscillations - be it music or a reciting voice - in numbers and thus to notate intelligible speech as well as incomprehensible noise in numerical form, side by side. This quantification of sounds and voices made it possible to create a new form of art, such as music that does not follow the rules of classical harmony, but which can measure out the transitions between sound and noise. Kittler refers to the operas of Richard Wagner, which feel their way across the range of tones and ultimately end in pure noise; or the electronic music of the twentieth century, which can emit frequencies that a human listener is unable to perceive. The signal-tonoise ratio increasingly becomes a factor that brackets out human concerns and is relevant only to technical systems (Kittler refers to Norbert Wiener's system for controlling anti-aircraft fire). The production of art can now be carried out by technical agents, meaning that the addressee of art becomes increasingly inhuman.

For - thirdly - this is how Kittler concludes his deliberations: with the marginalization of the arts and human beings. If technical media generate frequencies that humans are unable to perceive, or if these media inaugurate processes of communication that bracket out human beings and, as a result of high speeds or encryption techniques, take place exclusively between computers and machines, then human beings are no longer the referent and the subject of communication techniques and art (Krämer 2004: 217-218). The media have gone through a genesis in which human beings are no longer a point of reference. The god of prostheses, who has outsourced many of his shortcomings to tools and technical media, seems to be in the process of being overtaken by artificial intelligence. The movement that began with processes of disruptive interference, their elimination or their targeted implementation, ends in computer-controlled and cybernetic systems, which "condemn human beings to remain human beings" (Kittler 2014: 210).

\section{Works Cited}

Foucault, Michel (1981) “The Order of Discourse," in Untying the Text: A Post-Structuralist

Reader, ed. Robert Young (Boston; London; Henley: Routledge and Kegan Paul), 51-78. Gumbrecht, Hans Ulrich and K. Ludwig Pfeiffer (eds) (1988) Materialität der Kommunikation (Frankfurt a.M.: Suhrkamp). 
Kittler, Friedrich (1988) “Am Ende der Schriftkultur," in Der Ursprung von Literatur, ed. Gisela Smolka-Koerdt, Peter M. Spangenberg and Dagmar Tillmann-Bartylla (München: Fink), 289-300.

Kittler, Friedrich (1990) Discourse Networks, 1800/1900 (Stanford: Stanford UP).

Kittler, Friedrich (2014) "Protected Mode," in The Truth of the Technological World. Essays on the Genealogy of Presence, ed. Friedrich A. Kittler, with an Afterword by Hans Ulrich Gumbrecht (Stanford: Stanford UP), 209-218.

Krämer, Sybille (2004) “Friedrich Kittler - Kulturtechniken der Zeitachsenmanipulation," in Medientheorien. Eine philosophische Einführung, ed. Alice Lagaay and David Lauer (Frankfurt a.M.; New York: Campus), 201-224.

Schüttpelz, Erhard (2002) “'Get the Message Through'. Von der Kanaltheorie der Kommunikation zur Botschaft des Mediums: Ein Telegramm aus der nordatlantischen Nachkriegszeit," in Medienkultur der 50er Jahre, ed. Irmela Schneider and Peter M. Spangenberg (Wiesbaden: Westdeutscher Verlag), 51-76.

Shannon, Claude Elwood (1949) "Communication in the Presence of Noise," Proceedings of Institute of Radio Engineers 37.1, 10-21.

Shannon, Claude Elwood (1991 [1946]) "Communication Theory of Secrecy Systems," in Claude Elwood Shannon. Collected Papers, ed. N. J. A. Sloane and Aaron D. Wyner (Piscataway: Wiley-IEEE Press), 84-143.

Winthrop-Young, Geoffrey (2005) Friedrich Kittler. Zur Einführung (Hamburg: Junius). 
